\title{
Adubação mineral e orgânica na produtividade e aceitabilidade de pastejo do capim Elefante
}

\author{
Mineral and organic fertilization on forage yield and \\ grazing acceptability of elephant grass
}

Erika Tagima Marcelo ${ }^{[a]}$, Paulo Roberto de Lima Meirelles ${ }^{[b]}$, Marco Aurélio Factori[c], Vânia Luzia Fournou de Lima ${ }^{[\mathrm{d}]}$, Luciane do Carmo Seraphim ${ }^{[\mathrm{d}]}$, Janaina Conte Hadlich ${ }^{[\mathrm{b}]}$

[a] Zootecnista, Universidade Estadual Paulista Júlio de Mesquita Filho (UNESP), Botucatu, SP - Brasil, e-mail: erika_ tmarcelo@hotmail.com

[b] Zootecnistas, doutores em Zootecnia, Professor do Departamento de Melhoramento e Nutrição Animal, Universidade Estadual Paulista Júlio de Mesquita Filho (UNESP), Botucatu, SP - Brasil, e-mails: paulom@fmvz.unesp.br; jana.hadlich@ gmail.com

[c] Zootecnista, doutor em Zootecnia, Pós-Doutorando do Departamento de Melhoramento e Nutrição Animal, Universidade Estadual Paulista Júlio de Mesquita Filho (UNESP), Botucatu, SP - Brasil, e-mail: mafactori@yahoo.com.br

[d] Zootecnistas, mestrandas do Programa de Pós-Graduação em Zootecnia, Universidade Estadual Paulista Júlio de Mesquita Filho (UNESP), Botucatu, SP - Brasil, e-mails: fournou.vania@gmail.com; lucianeseraphim@yahoo.com.br

\section{Resumo}

A cama de frango apresenta grande diversidade de nutrientes e por isso pode melhorar a produtividade das pastagens, proporcionando capins com maior aceitabilidade para os animais. 0 objetivo deste trabalho foi avaliar a produtividade e a aceitabilidade pelo bovino em parcelas adubadas com cama de frango em substituição ao adubo inorgânico em pastagem de Pennisetum purpureum cv. Napier. Foram realizados três pastejos (nos ciclos do capim, a cada 42 dias) com animais mestiços da raça Nelore (380 kg de peso vivo). A área foi subdividida em cinco blocos com três parcelas de 6x7 metros, delimitadas externamente para livre acesso dos animais às parcelas. Nos três pastejos foram avaliadas três horas iniciais para quantificar a aceitabilidade dos animais às parcelas. Os tratamentos foram: T1 - cama de frango na dosagem de 20 t/ha, em uma aplicação; T2 - cama de frango na dosagem de 20 t/ha, dividida em 5 aplicações; T3 - ureia na dosagem de $70 \mathrm{~kg}$ de nitrogênio por hectare por ciclo, em delineamento em blocos ao acaso. As produtividades de massa seca foram diferentes em relação aos ciclos, não sendo diferentes entre tratamentos. A concentração de material morto foi maior no segundo corte, para T1. Houve maior aceitabilidade para os tratamentos T1 e T2. Pode-se inferir que a adubação com cama de frango em substituição ao adubo inorgânico, pode ser 
utilizada, pois mantêm a produtividade de massa, além de proporcionar excelente aceitação da forragem pelos animais.

Palavras-chave: Bovinos. Cama de frango. Pastagem. Ureia.

\section{Abstract}

Poultry litter has a great diversity of nutrients and can improve the productivity of pasture grasses, providing greater acceptability to animals. The objective of this study was to evaluate the productivity and acceptability by cattle in plots fertilized with chicken litter to replace inorganic fertilizer grazing Pennisetum purpureum cv. Napier. Three grazing cycles were performed (in cycles of grass, every 42 days) with crossbred Nellore animals (380 kg liveweight). The area was divided into five blocks with three plots of $6 x 7$ meters, bounded externally to free access of the animals. On the three grazings, first three hours were evaluated to quantify the acceptability of the animals to the plots. The treatments were: T1 - poultry litter at a dosage of $20 \mathrm{t} / \mathrm{ha}$ in one application; T2 - poultry litter at a dosage of $20 \mathrm{t} / \mathrm{ha}$, divided into 5 applications; T3 - urea dosage of $70 \mathrm{~kg}$ of nitrogen per hectare per cycle in randomized block design. Yields of dry matter were different in relation to the cycles, not being different between treatments. The concentration of dead material was higher in the second cut, to T1. There was greater acceptance for $\mathrm{T} 1$ and T2 treatments. It can be inferred that fertilization with chicken litter to replace inorganic fertilizer, can be used because it maintain productivity of matter and besides providing excellent acceptance of fodder for animals.

Keywords: Cattle. Chicken litter. Grazing. Urea.

\section{Introdução}

Na produção de leite ou carne em pastagem, o uso do sistema de pastejo de lotação rotacionada, quando comparado aos sistemas intensivos, vem somando em produtividade pelo seu baixo custo de implantação e manutenção para animais de baixa a média produção, no que tange a investimentos com instalações. No entanto, o uso de adubação química de manutenção (adubação nitrogenada) vem preocupando os produtores pelo aumento do custo de produção.

Sendo proibido o uso da cama de frango na alimentação de ruminantes, a utilização da mesma como adubo orgânico é a saída encontrada por avicultores e produtores de leite e carne para tornar seguro e rentável o destino desse resíduo da criação, bem como viabilizar o custo de produção em substituição ao adubo químico. Para tanto, sua proibição a partir de 2004 pela Instrução Normativa no. 15 de 06/05/2009 e Instrução Normativa no. 8 de 25/03/2004 do Ministério da Agricultura, Pecuária e Abastecimento (MAPA), foi uma importante medida preventiva para se evitar no Brasil os riscos potenciais da Encefalopatia Espongiforme Bovina (EEB), doença popularmente chamada de "mal da vaca louca".

Entretanto, segundo Menezes et al. (2004), para diminuir o impacto ao meio ambiente, a cama de frango deve ser aplicada seguindo conceitos técnicos em função da sua composição química e necessidade de nutrientes do solo. 0 produtor que optar por esse tipo de fertilização orgânica deve medir anualmente o balanço entre os nutrientes por meio da análise de solo.

Segundo Kiehl (1997), o efeito da matéria orgânica sobre a produtividade pode ser direto por meio do fornecimento de nutrientes ou pelas modificações das propriedades físicas do solo, melhorando o ambiente radicular e estimulando o desenvolvimento das plantas. No entanto, cabe ressaltar que o uso de adubos orgânicos promove a liberação lenta e gradual de nutrientes, com a vantagem de aumentar o teor de matéria orgânica do solo. Segundo Menezes et al. (2004), o adubo orgânico libera gradativamente macro e micronutrientes 
para a solução do solo à medida que o material orgânico vai sendo mineralizado, sendo a quantidade liberada dependente do grau de mineralização do composto, da matéria prima que deu origem ao composto e das quantidades aplicadas.

Assim, objetivou-se avaliar a produtividade do capim elefante e o comportamento animal por meio de preferência de pastejo em parcelas adubadas com adubo químico (ureia) e orgânico (cama de frango) em pastagem de Pennisetum purpureum cv. Napier.

\section{Material e métodos}

O experimento foi realizado em propriedade particular localizada na cidade de Botucatu (SP). A área utilizada foi de 860 metros quadrados onde já se encontrava implantada uma pastagem de Pennisetum purpureum cv. Napier, disposta em linha uniformizada 42 dias antes do início do experimento, assim como a adubação para a composição dos tratamentos. 0 solo característico é Latossolo Amarelo Ácrico e o clima da região é o tropical de altitude, com inverno seco e verão quente e chuvoso em que há precipitação média de $1300 \mathrm{~mm}$. Foram coletados diariamente, na área experimental, os dados de pluviosidade e temperatura em termômetro digital (máxima e mínima).

Para efeito de reposição de nutrientes do solo, foi realizada uma análise de solo na área buscando determinar as quantidades necessárias de calcário (em função da saturação por bases e pH) e outros nutrientes, como o fósforo e potássio.

Na Tabela 1 são apresentados os resultados da análise de solo e da cama de frango utilizados. Verificou-se os baixos níveis de fósforo $\left(5 \mathrm{mg} / \mathrm{dm}^{3}\right)$ e potássio $\left(0,8 \mathrm{mmol} / \mathrm{dm}^{3}\right)$, que foram corrigidos com a aplicação de superfosfato simples e cloreto de potássio. Em relação à cama de frango, destacam-se, principalmente, os teores de nitrogênio (N), com valores de $4,27 \%$, fósforo $\left(\mathrm{P}_{2} \mathrm{O}_{5}\right) 2,32 \%$ e potássio $\left(\mathrm{K}_{2} \mathrm{O}\right) 2,26 \%$.

No período experimental, as temperaturas mínimas encontradas foram maiores que $15{ }^{\circ} \mathrm{C}$ nos meses de outubro a fevereiro, favorecendo o crescimento da forragem (Tabela 2). Observa-se, ainda, que a precipitação apresentada foi maior nos meses

Tabela 1 - Valores referentes à análise de solo e cama de frango utilizadas no experimento

\begin{tabular}{|c|c|c|c|c|c|c|c|c|c|c|c|c|}
\hline \multicolumn{13}{|c|}{ Análise da terra } \\
\hline $\mathbf{P h}$ & M.O. & $\mathbf{P}_{\text {resina }}$ & $\mathrm{Al}^{3+}$ & $\mathrm{H}+\mathrm{Al}$ & $\mathbf{K}$ & $\mathrm{Ca}$ & $\mathrm{Mg}$ & SB & CTC & & V\% & $\mathbf{S}$ \\
\hline $\mathrm{CaCl}_{2}$ & $\mathrm{~g} / \mathrm{dm}^{3}$ & $\mathrm{mg} / \mathrm{dm}^{3}$ & \multicolumn{9}{|c|}{ - } & $\mathrm{mg} / \mathrm{dm}^{3}$ \\
\hline 5,3 & 11 & 5 & 1 & 17 & 0,8 & 19 & 6 & 25 & 42 & & 59 & --- \\
\hline \multicolumn{13}{|c|}{ Análise da cama de frango (\%) } \\
\hline $\mathbf{N}$ & \multicolumn{2}{|c|}{$\mathrm{P}_{2} \mathrm{O}_{5}$} & $\mathrm{~K}_{2} \mathrm{O}$ & & $\mathrm{Ca}$ & \multicolumn{2}{|r|}{$\mathrm{Mg}$} & S & \multicolumn{3}{|c|}{ MS } & MO \\
\hline 4,27 & \multicolumn{2}{|c|}{2,32} & 2,26 & & 2,47 & \multicolumn{2}{|r|}{0,5} & 0,59 & \multicolumn{3}{|c|}{87} & 61 \\
\hline
\end{tabular}

Fonte: Dados da pesquisa.

Tabela 2 - Temperaturas médias, máximas, mínimas e pluviosidade encontradas nos meses experimentais (outubro a fevereiro)

\begin{tabular}{lcccc}
\hline Meses experimentais & $\begin{array}{c}\text { Temperaturas } \\
\text { Médias - }{ }^{\circ} \mathbf{C}\end{array}$ & $\begin{array}{c}\text { Temperaturas } \\
\text { Máximas - }{ }^{\circ} \mathbf{C}\end{array}$ & $\begin{array}{c}\text { Temperaturas } \\
\text { Mínimas - }{ }^{\circ} \mathbf{C}\end{array}$ & $\begin{array}{c}\text { Precipitação } \\
(\mathbf{m m})\end{array}$ \\
\hline Outubro & 23,2 & 28,0 & 18,5 & 94 \\
Novembro & 25,3 & 30,4 & 20,1 & 67 \\
Dezembro & 26,3 & 30,4 & 22,3 & 242 \\
Janeiro & 26,9 & 30,84 & 23,1 & 330 \\
Fevereiro & 27,1 & 31,41 & 22,9 & 257 \\
\hline
\end{tabular}

Fonte: Dados da pesquisa. 
de dezembro a fevereiro, com valores mínimos de 5 a 6 milímetros por dia de chuva, sendo estes dados favoráveis para aumentar a produtividade do capim.

Os tratamentos utilizados foram: T1 - cama de frango na dosagem de 20 toneladas por hectare, aplicada de uma única vez, 30 dias antes do primeiro ciclo de pastejo (Instrução Normativa no. 15 e no. 8 - MAPA); T2 - cama de frango na dosagem de 20 toneladas por hectare dividida em 5 aplicações, respectivamente, nos 5 ciclos de pastejo de verão, porém utilizados para coleta apenas 3 ciclos, totalizando 12 toneladas de cama aplicados; T3 - ureia na dosagem de $70 \mathrm{~kg}$ de nitrogênio (N) por hectare (150kg de ureia), nos respectivos ciclos de pastejo.

A área utilizada para as parcelas apresentou declive de $12 \%$, sendo subdividida em 5 blocos com 3 parcelas de $6 \times 7$ metros cada(uma para cada tratamento) e corredores de 1 metro entre as parcelas, descontando-se as bordaduras, sendo a área total cercada para ser pastejada pelos animais com livre acesso às parcelas do capim adubadas com cama de frango ou ureia.

Foram efetuados três pastejos (ciclos iniciais de verão) a cada 42 dias, sendo este período considerado após a uniformização seguida da adubação da área e entre os cortes ou pastejos realizados com seis animais mestiços da raça Nelore (Nelore x sem raça definida) e peso vivo médio de $380 \mathrm{~kg}$, marcados à tinta no dorso para serem mais facilmente visualizados.

Foram avaliadas, em cada pastejo, as três horas iniciais buscando quantificar a preferência ou aceitabilidade dos animais pelas parcelas adubadas (tratamentos) com adubo orgânico (cama de frango) e adubo químico (ureia). As avaliações foram a cada 5 minutos, determinando assim o tempo total efetivo que cada animal permaneceu dentro de cada parcela nas três horas avaliadas, em função do seu livre acesso aos tratamentos (parcelas).

Nos ciclos de pastejo de verão (Novembro a Janeiro), realizaram-se três cortes da forragem a $0,45 \mathrm{~m}$ de altura, pelo método do quadrado. As amostras foram pesadas e retirou-se uma subamostra de 0,150 kg para determinação da matéria seca em estufa a $60 \stackrel{\circ}{-}$ por 72 horas, assim como posterior determinação da matéria parcialmente seca e, consequentemente, da produtividade dos tratamentos.
Nos três ciclos de pastejo, após o corte da forragem, foram retiradas subamostras de 0,500 kg para separação morfológica em lâmina foliar, colmo (colmo + bainha) e material senescente, que após pesados foram também secos em estufa a $60 \stackrel{\circ}{\mathrm{C}}$ por 72 horas para determinação da massa seca e produtividade das frações.

0 experimento foi desenvolvido no delineamento em blocos casualizados ( 5 blocos com 3 parcelas por bloco). As análises estatísticas foram executadas por meio do programa SAEG - Sistema de Análises Estatísticas e Genéticas, versão 9.0 (UFV, 2000) com nível de significância $(\mathrm{P}<0,05)$.

\section{Resultados}

As produtividades de massa seca encontradas (Tabela 3) revelaram diferença significativa entre os cortes, podendo estar relacionada ao clima no mês de fevereiro, que apresenta temperatura favorável e um regime de chuvas equilibrado e adequado para o desenvolvimento da produção. Não foram constatadas diferenças entre os tratamentos, observando-se naqueles que utilizaram a cama de frango comportamento semelhante aos de que receberam ureia, no que tange à produtividade do capim durante o período experimental. 0 aporte nitrogenado provindo do adubo orgânico foi suficiente para que a forragem expusesse seu potencial produtivo e, assim, se equivalesse ao adubo inorgânico na forma de ureia.

Tabela 3 - Produtividade de massa seca de forragem (kg/ ha) em função dos pastejos e adubação com ureia ou cama de frango em dose única ou parcelada

\begin{tabular}{lccc}
\hline & \multicolumn{3}{c}{ Pastejo } \\
\cline { 2 - 4 } Tratamentos & Novembro & Dezembro & Janeiro \\
& $-\mathbf{1 0}^{\circ}$ & $-\mathbf{2}^{\mathbf{0}}$ & $-\mathbf{3}^{\mathbf{0}}$ \\
\hline Cama 1 aplicação & $792 \mathrm{c}$ & $2704 \mathrm{~b}$ & $5219 \mathrm{a}$ \\
Cama 5 aplicações & $728 \mathrm{c}$ & $2885 \mathrm{~b}$ & $6597 \mathrm{a}$ \\
Ureia & $779 \mathrm{c}$ & $2882 \mathrm{~b}$ & $4963 \mathrm{a}$ \\
\hline
\end{tabular}

Nota: Médias seguidas de letras minúsculas diferentes na mesma linha diferem entre si pelo teste de Tukey $(P<0,05)$.

Fonte: Dados de pesquisa.

Na Tabela 4, estão apresentadas as produtividades relacionadas às percentagens de folha, colmo e material senescente. Não houve diferenças significativas 
para os tratamentos utilizados. No entanto, observou-se diferença entre os períodos de pastejo avaliados devido, principalmente, às condições climáticas e produtividades. Houve maior valor para material senescente, no segundo pastejo, sendo superior no tratamento com cama de frango em uma aplicação.

Tabela 4 - Produtividade $(\mathrm{kg} / \mathrm{ha}$ ) de folha, colmo e material senescente nos ciclos de pastejos (42 dias)

\begin{tabular}{lccc}
\hline & \multicolumn{3}{c}{ Produtividade } \\
\cline { 2 - 4 } Tratamentos & Folha & Colmo & $\begin{array}{c}\text { Material } \\
\text { Senescente }\end{array}$ \\
\hline (*) Primeiro pastejo & (1 de novembro) $-\mathbf{4 2}$ & dias de rebrote \\
\hline Cama 1 aplicação & 498 & 170 & 123 \\
Cama 5 aplicações & 443 & 164 & 121 \\
Ureia & 620 & 125 & 90 \\
\hline
\end{tabular}

$\left.{ }^{* *}\right)$ Segundo pastejo (12 de dezembro) - 42 dias de rebrote

\begin{tabular}{llll}
\hline Cama 1 aplicação & 1680 & 600 & 425 a \\
Cama 5 aplicações & 1458 & 501 & 168 b \\
Ureia & 2139 & 468 & 275 b \\
\hline (***) Terceiro pastejo (24 de janeiro) & - 42 dias de rebrote \\
\hline Cama 1 aplicação & 3386 & 1148 & 782 \\
Cama 5 aplicações & 3750 & 1251 & 990 \\
Ureia & 3077 & 1091 & 750 \\
\hline
\end{tabular}

Legenda: ${ }^{* * *},{ }^{* * *}$ - Diferença estatística entre os pastejos da forragem pelo teste de Tukey $(\mathrm{P}<0,05)$.

Nota: Médias seguidas de letras minúsculas diferentes na mesma coluna diferem entre si pelo teste de Tukey $(\mathrm{P}<0,05)$

Fonte: Dados da pesquisa.
Para os dados referentes à aceitabilidade no pastejo, verificou-se que nas três horas iniciais avaliadas houve preferência para os tratamentos que receberam adubação com cama de frango com médias de 60,8 e 50,8 minutos de pastejo, adubados de uma só vez (C1) e parceladas (C5), respectivamente (Figura 1). Entretanto, pode-se inferir que a cama de frango contribui para a maior aceitabilidade, embora os dados de fibra em detergente neutro e consumo por meio de marcadores não tenham sido avaliados. Para tanto, considerando os dados de produção forrageira semelhantes para ambos os tratamentos com adubo orgânico e inorgânico, a preferência pode ser considerada maior em função do tempo de pastejo.

\section{Discussão}

O efeito da matéria orgânica sobre a produtividade pode ser direto por meio do fornecimento de nutrientes ou pelas modificações das propriedades físicas do solo, melhorando o ambiente radicular e estimulando o desenvolvimento das plantas. Segundo Konzen (2003), a cama de frango contém altas concentrações de elementos de dejeções, pois as aves têm baixos índices de aproveitamento de suas rações (de 40 a $60 \%$ apenas), sendo o restante eliminado via dejetos.

Favoretto, Rodrigues e Tupinambá (1988), trabalhando com capim-colonião não adubado e com

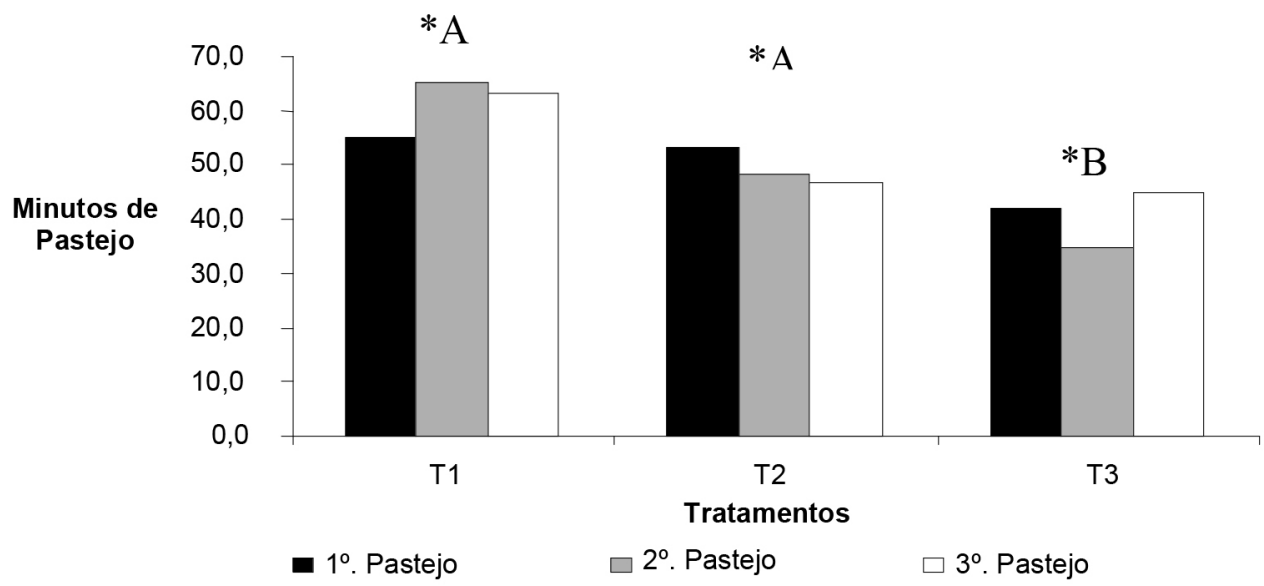

Figura 1 - Tempo de Pastejo (Aceitabilidade) em função dos tratamentos.

Legenda: T1 - Cama de frango adubado em parcela única; T2 - Cama de frango adubado nos ciclos de pastejo; T3 - Adubado com ureia;

Nota: (*) Diferença entre tratamentos (Tukey a 5\%).

Fonte: Dados da pesquisa.

Rev. Acad., Ciênc. Agrár. Ambient., Curitiba, v. 12, n. 3, p. 191-197, jul./set. 2014 
adubação nas doses de 50 e $100 \mathrm{~kg} /$ ha de N, durante o verão (novembro-março), verificaram aumento na produção de massa seca em função da elevação dos níveis de N. Outro importante fator, ainda, é a estação da seca, em que as gramíneas tropicais apresentam baixa disponibilidade de forragem e obrigam os produtores a suplementarem o rebanho, elevando o custo de produção. Pinheiro (2002) observou produções médias de massa seca do capim-tanzânia de até $3.553 \mathrm{~kg} /$ ha no verão, sendo que no inverno o valor máximo obtido foi de $1.479 \mathrm{~kg} / \mathrm{ha}$.

Como mencionado anteriormente, a produtividade forrageira está totalmente relacionada com as características climáticas do local. As temperaturas encontradas durante o período experimental foram maiores que $15{ }^{\circ} \mathrm{C}$, o que não limitou o crescimento forrageiro. Não foi limitante também o fator água, uma vez que, segundo Lopes et al. (2003), os valores observados são suficientes ( 5 a 6 milímetros por dia de chuva). Assim, considerando produtividades mínimas de $790 \mathrm{~kg} / \mathrm{ha}$ nos primeiros ciclos de pastejo, os resultados foram satisfatórios em função do efeito da época seca na produção de forragem.

A utilização da cama de frango como fertilizante para forrageiras tem a grande vantagem de disponibilizar nutrientes, após aplicação, e manter a liberação residual nos anos subsequentes. Segundo Malavolta et al. (1981), no caso do nitrogênio, 50\% é disponibilizado no primeiro ano, $20 \%$ no segundo e $30 \%$ em anos seguintes. No presente trabalho, o efeito da adubação orgânica foi detectado já no primeiro ciclo de pastejo, mesmo para o tratamento com cama dividido em ciclos de pastejo (4 toneladas por ciclo), sugerindo que as dosagens poderão ser diminuídas em futuros estudos, aumentando a eficiência do uso do adubo orgânico.

A relação lâmina/colmo é de grande importância do ponto de vista nutritivo e de manejo das espécies forrageiras. Segundo Andrade (1997), a composição química da forragem varia em função da idade, da parte da planta (lâmina ou colmo), da época do ano e da fertilidade do solo, o que pode explicar a preferência dos animais pelos tratamentos que utilizaram a cama de frango como fonte de nitrogênio. 0 maior aporte de nutrientes no solo, bem como o seu condicionamento, implicou em uma forragem mais aceita, mesmo com dados semelhantes em função das percentagens de folha, colmo e material senescente.
Em muitos trabalhos se descreve o efeito da adubação nitrogenada sobre o teor de proteína das plantas (RIBEIRO, 1995). Em sua maioria, os trabalhos que descrevem o valor nutritivo de plantas forrageiras do gênero Pennisetum são realizados sob corte, não havendo interação com o animal por serem embasados em estudos de frequência de corte fixa relacionada com intensidade de corte (altura do resíduo).

Em relação à estrutura da pastagem, Laca e Lemaire (2000) definem a distribuição espacial da biomassa aérea das plantas como uma comunidade. De forma geral, é descrita por variáveis que expressam a quantidade de forragem existente de maneira bidimensional, sendo elas a estrutura da pastagem e a dimensão vertical e horizontal da distribuição da massa seca no perfil da pastagem, relacionando altura e densidade desta massa sobre a ingestão de forragem (BURLISON; HODGSON; ILLIUS, 1991; TORRES-RODRIGUES et al., 1997). Tais características podem facilitar a apreensão de forragem pelos animais (STOBBS, 1973), pois a insuficiência ou a inacessibilidade de forragem pode restringir o consumo, o que não foi verificado no presente estudo em função das mesmas produtividades encontradas.

Ao longo do tempo, a pastagem passa por fases que se caracterizam por investimentos em estruturas vegetativas ou reprodutivas, aéreas ou subterrâneas, podendo estar relacionadas à idade ou adubação do solo para formação de folhas (CARVALHO et al., 2001).Os dados corroboram o presente estudo, sendo igual para os tratamentos e diferenciando-se apenas os cortes em épocas diferentes, favorecidos por melhores fatores climáticos (verão).

Estudos que acrescentem relações de produtividade e adubação orgânica com o uso de pastejo são importantes linhas de pesquisa, a fim de quantificar e mensurar os efeitos da adubação na produtividade, bem como na estrutura da pastagem.

\section{Conclusões}

Pode-se inferir que a adubação com cama de frango em substituição ao adubo inorgânico pode ser utilizada, pois mantêm a produtividade de massa e proporciona excelente aceitação da forragem pelos animais. 


\section{Referências}

ANDRADE, A. C. Produtividade e valor nutritivo do Capim-Elefante (Pennisetum purpureum Schum. cv. Napier) sob diferentes doses de nitrogênio e potássio. 1997. 52 f. Dissertação (Mestrado em Zootecnia) Universidade Federal de Viçosa, Viçosa, 1997.

BURLISON, A. J.; HODGSON, J.; ILLIUS, A. W. Sward canopy structure and bite dimensions and bite weight of grazing sheep. Grass and Forage Science, v. 46, n. 1, p. 29-38, 1991. doi:10.1111/j.1365-2494.1991.tb02205.x.

CARVALHO, P. C. F. et al. Pastagens altas podem limitar o consumo dos animais. In: REUNIÃO ANUAL DA SOCIEDADE BRASILEIRA DE ZOOTECNIA, 38., 2001, Piracicaba. Anais... Piracicaba: SBZ, 2001. p. 265-268.

FAVORETTO, V.; RODRIGUES, L. R. A.; TUPINAMBÁ, C. F. Estudo do nitrogênio na produção e composição bromatológica do capim-colonião e seus aspectos econômicos. Científica, v. 16, n. 1, p. 71-78, 1988.

LACA, E. A.; LEMAIRE, G. Measuring sward structure. In: MANNETJE, L.; JONES, R.M. (Eds.) Field and laboratory methods for grassland and animal production research. Wallingford: CABI Publication, 2000. p. 103-121.

LOPES, R. S. et al. Disponibilidade matéria seca em pastagens de capim elefante irrigadas. Ciência e Agrotecnologia, v. 27, n. 6, p. 1388-1394, 2003. 10.1590/ S1413-70542003000600025

KIEHL, J. C. Adubação orgânica de culturas forrageiras. In. SIMPÓSIO SOBRE ECOSSISTEMAS DE PASTAGENS, 3., 1997, Jaboticabal. Anais... Jaboticabal: FCAV/Unesp, 1997. p. 208-250.

KONZEN, E. A. Fertilização de lavoura e pastagem com dejetos de suínos e cama de aves. In: SEMINÁRIO TÉCNICO DA CULTURA DE MILHO, 5, 2003, Videira. Anais... Videira, SC, 2003.

MALAVOLTA, E. Manual de química agrícola: adubos e adubação. São Paulo: Editora Ceres, 1981.

MENEZES, J. F. S. et al. Cama de frango na agricultura: perspectivas e viabilidade técnico e econômica. Rio Verde: FESURV, 2004. (FESURV. Boletim Técnico, 3).

MINISTÉRIO DA AGRICULTURA, PECUÁRIA E ABASTECIMENTO - MAPA. Instrução Normativa nํ․ 8, de 25 de março de 2004. Proíbe em todo o território nacional a produção, a comercialização e a utilização de produtos destinados à alimentação de ruminantes que contenham em sua composição proteínas e gorduras de origem animal. Diário Oficial [da] União, de 26 de março de 2004, Seção 1, página 5.
MINISTÉRIO DA AGRICULTURA, PECUÁRIA E ABASTECIMENTO - MAPA. Instrução Normativa no‥ 15, de 26 de maio de 2009. Regulamentar o registro dos estabelecimentos e dos produtos destinados à alimentação animal. Diário Oficial [da] União, de 28 de maio de 2009, Seção 1.

PINHEIRO, V. D. Viabilidade econômica da irrigação de pastagem de capim Tanzânia em diferentes regiões do Brasil. 2002. 85 f. Dissertação (Mestrado em Irrigação e Drenagem) - Escola Superior de Agricultura "Luiz de Queiroz", Universidade de São Paulo, Piracicaba, 2002.

RIBEIRO, K. G. Rendimento forrageiro e valor nutritivo do capim elefante "Anão", sob cinco doses de nitrogênio ao atingir 80 e $120 \mathbf{~ c m}$ de altura. 1995. 60 f. Dissertação (Mestrado em Zootecnia) - Universidade Federal de Viçosa, Viçosa, 1995.

STOBBS, T. H. The effects of plant structure on the intake of tropical pastures. II. Differences in sward Structure, nutritive value and bite size of animals grazing Setaria anceps and Chloris gayana at various stages of growth. Australian Journal of Agricultural Research, v. 24, n. 6, p. 821-829, 1973. doi:10.1071/AR9730821.

TORRES-RODRIGUES, A. et al. Cattle diet preference and species selection as influenced by availability. Proceedings of the New Zealand Society of Animal Production, v. 57, p. 197-198, 1997.

UNIVERSIDADE FEDERAL DE VIÇOSA - UFV. Sistema de Análise Estatística e Genéticas - SAEG. Versão 9.0. Viçosa: UFV, 2000.

Recebido em: 05/06/2014

Received in: 06/05/2014

Aprovado em: 04/12/2014 Approved in: $12 / 04 / 2014$ 